well developed, but with her muscles in a very flabby condition. She was lying flat on her back in bed in an arynamic state, with the face pale and expressionless. Her diathesis was not well marked. Temperature $101 \cdot 4^{\circ}$. Tongue a little coated, very flabby, and with the fungiform papillir abnormally raised. Appetite bad, with thirst, and the odour of her breath disagreeable. There was tenderness on pressure in the epigastrium, but in every other respect the abdomen was normal. 'There was no visible apex beat, and the cardiac impulse was almost imperceptible to palpation. The first cardiac sound was inaudible, with some accentuation of the second heart sound in the mitral area. There were no murmurs present, and the action of the cardiac muscle was extremely weak. Pulse 110, rhythm regular, and in character very small and weak, with deficient filling of the arteries. I gave her strophanthus and nux vomica, together with astringent powders for her diarrhoca, and her case ended favourably on June $3 \mathrm{rd}$, when she was crossed off my list in an excellent state of health.

CASE 5.-MIrs. B-, ared fifty-seven years, a chronic invalid, who complained of a variety of variable symptoms, but principally of dyspncea and weakness. I visited her for the first time on Noy. 13th last, when she presented the following condition. A short, stout woman, rather pale in the face, with a melancholic expression. Lips pale, of a bluish colour, and the teeth mostly all decayed. The tongue was coated down the centre with a yellowish-brown fur, heing clean at each side of this band. There was anorexia, some thirst, with a sense of flatulent distension, and at times nausea and even vomiting. The liver appeared to be a little roughened on palpation, contracted slightly, and was tender to pressure. No impulse could be felt in the procordia, and the quality of the heart sounds was very weak on auscultation in the various areas. The pulse was normal in frequency, but remarkably weak and compressible. The other systems were normal. This patient had been greatly addicted to drink for years, and was found to be suffering from chronic dipsomania, with cirrhosis of her liver. Owing to the extremely weakened condition of her circulatory system, I determined to try her with the following mixture: Tincture of strophanthus, $1 \mathrm{dr}$. tincture of nux vomica, $1 \frac{1}{2} \mathrm{dr}$. ; tincture of capsicum, $1 \mathrm{dr}$. ; decoction of cinchona to $8 \mathrm{oz}$.; two tablespoonfuls to be taken thrice daily. She received considerable benefit from taking this mixture, especially so far as her circulatory system was concerned. Her heart improved so much as to be felt on palpation, and her craving for alcoholic drinks was not by any means so great. I think that possibly her desire for so much alcohol was in a great measure due to the weakened state of her circulation, with an improper flling of her cerebral arteries causing anæemia of the brain and in order to arouse this flagging circulation she drank alcohol freely.

CASE 6.-H. S—, aged fifty-nine, complained of being short of breath on the least exertion, or in stooping to lace his boots, or even to pick anything from the floor. $\mathrm{He}$ also felt a pain in the region of the heart. He had suffered from winter bronchitis for the last four years. He was a short, excessively stout person, with a pale face and gouty diathesis. It required very careful palpation to detect any impulse of the heart, as it was so very weak in its action, but natural in position. In quality the cardiac sounds were very weak at the different areas, especially the first sound in the mitral area. Pulse 78, regular, but weak, soft, and very compressible. The arteries were not degenerated. Diagnosis; Adipose infiltration upon and between the cardiac muscular fibres, causing this heart failure. The tincture of strophanthus and nux vomica, in five-minim doses of each three times a day, afforded him with very great relief. His lips have now become red, being pale and blue before. The face has also assumed a ruddy appearance. The cardiac muscle acts strongly, and the apex beat can be distinctly felt on palpation. The pulse is now 70 , very much stronger in character, and the tone is excellent.

CASE 7.-G.S-, aged thirty-four years, came under my care in September, 1887, suffering from enteric fever, having had a very severe attack of this fever, lasting for fifty-three days, and with the intervention of several conplications, the principal of them being pneumonia, hremorthage from the bowels, and thrombosis of the veins of the right leg. On Oct. 27th his circulation became very weak, and he was in imminent danger of death from cardiac failure. The state of his circulatory system was then as follows: Faintness and dyspncea, with a marked tendency to syncope The apex beat was impercentilsle to palpation. In the mitral area both the heart sounds were inaudible; but as the cup of the stethoscope was advanced towards the base of the heart the second sound gradually became audible, and it was distinctly so in the aortic area. Pulse 79 , intermittent in rhythm, and remarkably feeble. The arteries were imperfectly filled with blood. The severity of the enteric fever had undoubtedly left this patient with a considerable amount of fatty degeneration of the muscular fibres of the heart. He was ordered a mixture containing a minim and a half of the tincture of strophanthus, combined with nux vomica, every half-hour. As he improved, the medicine was given less often, being ordered every hour, and afterwards every two and four hours. In the seventh mixture the nux vomica was left out entirely, and it was prescribed to be taken three times a day. This medicine evidently saved his life, and he resumed his usual employment last February. He continues to work, and now feels as strong as he ever did.

Remarks. - The most interesting features connected with the first, second, and the sixth cases are derived from the fact of the patients having taken large quantities of digitalis from time to time under the treatment of different medical gentlemen, and this without any very great improvement in any of them. With both of the first two patients I immediately supplanted digitalis by strophanthus; consequently I was in a position to weigh accurately from a clinical aspect the effect of these two drugs in mitral disease. I believe that I can conscientionsly assert that our new remedy is vastly superior to the older one (digitalis), especially in mitral complaints and cardiac failures. It thoroughly established compensation, and caused extremely irregular and also intermittent pulses to become perfectly regular, in cases where digitalis had previously failed. It appears to act as a cardiac tonic by stimulating the cardiac muscle into a greater state of contraction, and also by prolonging this state of systole. Acting thus, it raises the blood pressure within the arteries in the various organs, as manifested by the diuresis produced in these cases; and in the fifth case by raising the tone of the cerebral circulation. It also seems to slow the rhythm of the heart, and to steady its diastole, giving it more time to nourish itself through the coronary arteries. In my opinion, when a patient is properly under theinfluence of strophanthus, it prevents an already dilated heart from assuming the same amount of dilatation after each systole as there previously existed, and this depends on the power this drug possesses in maintaining the cardiac muscular fibres in a state of contraction. I have never found strophanthus to cause the heart to beat irregularly, or to make the pulse more rapid in action, even when given in very large and continued doses, as is repeatedly observed with large doses of digitalis; neither is it cumulative in its action. The addition of nux vomica seems to accelerate and aid the therapeutical effects of strophanthus hispidus.

Anglesey.

\section{CASE OF EXCAVATED MALIGNANT TUMOUR OF THE LUNG.}

BY GRAHAM STEELL, M.D.,

ASSISTANT PHYSICIAN TO THE MAYCHESTER ROYAL INFIRMARY.

W. L_- aged forty-five, a tramcar guard, was admitted into the Manchester Infirmary on Feb. 27th, 1888. He had been in good health till May, 1887, when he suffered from an attack of hæmoptysis, for which he was treated in the infirmary. From this time his health gradually deteriorated, although cough and expectoration did not become features of his illness till the beginning of winter. He began to attend the out-patient room of the infirmary in August, when no physical sign of pulmonary disease could be detected; notwithstanding this fact and the absence of a tubercular family history, the case was regarded as one of phthisis. He attended more or less regularly during the winter, but his chest was not again examined for some time. At one of his visits he complained of a good deal of pain in his chest, and on examining it I was surprised to find the following physical signs: absolute dulness of the upper portion of the right lung, accompanied by great sense of resistance on percussion, and absence of breath sounds over 
the dnll area, except in the supra-spinous region and upper inter-scapular region, where a few moist sounds were audible, along with a feeble indeterminate breath sound. The veins of the right upper extremity were noticed to be decidedly enlarged. In January he expectorated a considerable quantity of very fetid matter, and from this time his breath became offensive, occasionally unbearably so. $\mathrm{He}$ brought up large quantities of sputa at intervals.

The patient's health was evidently fast declining, and, as I had come to the conclusion that his illness was not phthisis in the ordinary sense, I took him into the infirmary. The physical signs at the time of admission were as follows. On inspection, the upper part of the chest on the right side looked distinctly fuller than the left, while its movement was almost annulled. Below, the movements of the chest on the right side and the intercostal depressions appeared natural. On percussion in the infra-clavicular region a simply dull sound was elicited, but on strong percussion a decided though obscure tympanitic resonance became audible; and when the patient openerl his mouth a forcible stroke produced imperfectly-developed cracked pot sound. In the right supra-clavicular and clavicular regions, and behind down to the level of the spine of the scapula, there was dulness. In front the dulness did not pass across the micldle line. On auscultation, there was absence of breath sounds over the dull area in front; belind, an indeterminate breath sound, accompanied by a few obscure moist sounds, was heard. The veins of the upper extremity and infraclavicular region were distended, and the right external jugular vein seemed fuller than the left. The sputa were fairly copious in amount and extremely offensive. The right pupil was smaller than the left. Before death, which took place on March 7 th, certain changes had occurred. The veins had become more distended, and below the outer half of the clavicle a soft, though not fluctuating, swelling, which did not become larger during coughing or smaller during a deep inspiration, had developed; in front, the dulness had extended to a slight extent across the niddle line ; behind, the dulness had diminished, having given place to a resonance not very dissimilar to that of the corresponding region of the opposite side; abundant moist sounds had become audible over the left lung and unaffected portion of the right lung, evidently owing to oederna. The temperature during the nine days over which morning and evening olservations were made only rose above normal twice, reaching on these occasions $100^{\circ} \cdot 6^{\circ}$ and $101^{\circ}$.

The case presented clinically several interesting peculiarities, but it is to be regretted that the sputa were not examined microscopically, as they might have cleared up the nature of the cavity, the existence of which was rendered probable by the symptoms and signs. The following facts represent the clinical evidence which examination of the case afforded.

A.-Firstly, as to symptoms. 1. An illness beginning with hæmoptysis, followed by indefinite failure of health, cough and expectoration not being present for several months. 2. The complaint of a great deal of local pain. 3. Fetid expectoration, large quantities of which were brought up at intervals, after the manner which we know to be suggestive of a cavity in the lung.

B. - Secondly, as to physical signs. 1. The fulness of the upper part of the chest on the right side, combined with impaired movement of the same part. 2 . The distension of the veins of the arm and neck, the subclavian being evidently nore involved than the jugular. 3. The contraction of the right pupil. 4. The, at first absolute, dulness of the upper lobe of the right lung; obscure tympanitic resonance with cracked-pot sound on forcible percussion becoming subsequently developed in front. Behind, at a still later period, the occurrence of a similar diminution of dulness, the resonance, however, not possessing tympanitic quality. 5. 'The essential limitation of dulness to the affected side. Extension across the middle line was only noticed during the last few days of life, and then in very trifling amount.

The conclusions that could be legitimately drawn from the clinical facts just noted were, I think, these:-1. That the disease had begun in the lung $(11, B 5)$. 2. That the whole of the upper lobe of the right lung was more or less consolidated (B 4). 3. That the upper lobe of the right lung contained a cavity (A 3, B 4). 4. That, whatever the cause of the consolidation, it was such as to cause centrifugal pressure (A 2; B 1, 2, 3).

It is usually and rightly believed that a mediastinal dulness differs from a lung dulness by passing across the middle line on the one hand, and on the other by its not involving the whole of the upper lohe of the lung so that it does not reach the costo-humeral angle, much less the posterior aspect. In these respects the dulness present in the case before us corresponded to a lung dulness, rather than to a mediastinal dulness, al though at last to a very slight extent the middle line was transoressed. Intra-thoracic tumours are generally mediastinal, and rarely pulmonary. In the present case the evidence from symptoms as well as signs pointed to thelung as its seat, supposing, from the pressure symptoms and signs, that a tumour existed. Lastly, granting that there was a tumour of the lung, it was necessary to admit that the tumour was excavated. Lung tumours are rare, excavated lung tumours excessively so.

Post-mortem cxamination by Dr. HarRIs, pathologist to the infimary.-Pleure: Both sides presented very tough old adhesions, which were firmer on the right than on the left side. On the right they were so tough as to require very rreat labour to remove the richt lung from the chest. There was no pleural cavity remaining on the right side, and in the little space left on the opposite side there was no effusion. Lungs: The uppermost lobe of the right lung was roluminous, extending as far as, but not beyond, the median line in front. The whole of the interior of that lobe was hollowerl out into an irregular cavity, which was filled with thick greenish-yellow material, which to the naked eye looked like pus, and emitted a very foul and peculiarly sickly odour. The walls of the cavity were very irregular, and formed by a soft greyish-white new growth. The growth forning the walls was in very small amount; in the greater part of the circumference of the cavity it did not exceed three-quarters of an inch in thickness. At the upper part of the cavity, however, there was a mass the size of a Tangerine orange, which projected into the interior of the space. It appeared as though there had been a large growth occupying the whole of the uppermost lobe, which had broken down in the centre, forming a space not unlike an alscess cavity. The growth was very soft, of greyish-white uniform appearance, with no indication of there being an alveolar structure. The appearance was uniform, like that of the round-celled sarcoma or the soft lympho-sarcomata. The growth everywhere extended up to the visceral layer of the pleura, and only at a few points could any trace of lung tissue be seen. The pleura over the cavity was only slightly thickened, and was adherent, as elsewhere, to the chest wall. The middle and lowermost lobe presented no abnormal appearances; there was no growth in either, nor in the pleura over either lobe. Percussion over the cavity in the uppermost lobe after the lung was removed from the body, but before any incision was made into the organ, gave a shallow tympanitic note. The left lung presented no abnormal appearance except in the apex, where there was a well marked cicatrix and puckering of the apex. The apex was depressed over an area the size of a half-crown piece, in consequence of the cicatrix in the lung tissue beneath. No caseous deposit. The pericardium presented no abnormal appearance. The lieart showed engorgement of the right side with black blood, partly fluid, partly coagulated; no other abnormal appearance. The trachea presented no abnormality. The mucous mentbrane of the large bronchi was hyperamic. From the bronchus leading to the uppermost lobe of the right lung was exuding some foul material similar to that found in the cavity in the corresponding lung. The liver weighed $31 \mathrm{~b} .8 \mathrm{oz}$. The spleen weighed $6 \mathrm{oz}$; it was pale and somewhat soft, but in other respects presented noabnormalappearance. The kidneys were somewhat soft, but were otherwise normal. The osophagus and stomach were healthy, as were also the peritoneum, intestine, and rectum. Microscopic exa mination of the tumour showed it to be a lympho-sarcoma. Manchester.

West Kent Mhdico-Chirurgical Society. - The first meeting of the thirty-third session (1888-89) was held at the Royal West Kent Dispensary, Greenwich-road, on Oct. 12th, when the following officers for the ensuing session (1888-89) were elected, after which the President delivered the inaugural address: Presiden :-Dr. Peter Horrocks. Vice-Presilents: Messrs. Thomas Moore and J. Poland. Council : Drs. Ernest Clarke and Alexander Forsyth; Messrs. G. H. Cable, Peter Cooper, Mc Gavin, J. Brindley Janes, and Fredk. Moon. Treasurer: Dr. Prior Purvis. Sec. H. W. Roberts. Librarian: Dr. ErnestClarke. 